\title{
Examining CAATTs Implementation by Internal Auditors in the Public Sector
}

\author{
Aidi Ahmi", Siti Zabedah Saidin, and Akilah Abdullah \\ Tunku Puteri Intan Safinaz School of Accountancy, Universiti Utara Malaysia
}

\begin{abstract}
Computer Assisted Audit Tools and Techniques (CAATTs) are not new for auditors, and it needs to be adopted to gain the audit efficiency and effectiveness especially in a current era of technology. This paper examined the implementation of CAATTs by internal auditors in the public sector. Accordingly, this research reports the results from 12 interviews made with internal audit departments in public sector in both federal and state level in Malaysia. This research found that the implementation of CAATTs by internal auditors in public sector is still low due to lack of expertise, high implementation and maintenance cost, limited access of auditee's data, and most of them prefer to conduct the audit manually. Furthermore, it is not mandatory for them to use CAATTs. The evidence is a contrast with the encouragement made by the government to improve the IT usage in public sector. The results implied that training for future auditors in CAATTs to ensure the successful implementation is crucial. For CAATTs to be a success, the head of internal audit also must have the awareness about the importance of CAATTs as well as enforcement of its implementation.
\end{abstract}

Keywords: CAATs, CAATTs, IT Adoption, Computerized Auditing, Public Sector

JEL Classification Code: M42

Paper Type: Research

\section{INTRODUCTION}

The objective of the internal audit department according to Perbendaharaan Malaysia (2004) is to help the organization achieve its purpose through a systematic, disciplined approach to evaluate and determine the effectiveness of control and governance processes. To achieve these objectives, auditors need to apply sufficient tools and techniques suitable with the data and information available in this digital age. Information technology (IT) is affecting every business as well as all the professions in every sector and industry.

*Corresponding author: E-mail: aidi@uum.edu.my 
According to Abu-Musa (2008), IT increases the accuracy and speed of transaction processing and can lead to competitive advantages for many organizations regarding operational efficiency, cost savings and reduction of human errors. Employees and customers also must cope with the development and advance of the technology. Auditors are also no different. International Federation of Accountants (IFAC) (2006) stressed the significance of using technology in their standard for a professional accountant and put it as one of the competency requirements for audit professionals.

With the implementation of e-government, the advanced of technologies and various computerized applications in the public sector, for sure that all the data are stored digitally. Thus, auditors should also shift their methods into digitalized tools and techniques. According to Weidenmier and Ramamoorti (2006), auditors need to use appropriate technology to increase their efficiency and effectiveness. It is important to emphasize that the use of technology especially CAATTs in auditing is a must and every internal audit department should put it as a high priority although it is not mandatory for the auditor to use it.

However, findings from the recent studies on the adoption of information technology (IT) especially in the usage of Computer Assisted Audit Tools \& Technique (CAATTs) by auditors are still low (Ahmi et al., 2016; Ahmi \& Kent, 2013). Notwithstanding with the benefits offered and massive potential of CAATTs, the reasons for non-adoption of CAATTs still needs to be investigated and understood.

This study examined the implementation of CAATTs by internal auditors in public sector. This paper aims to discuss the implementation of CAATTs in Malaysia, covering the status of the implementation, and any recommendation to provide better audit effectiveness and efficiency. The discussion includes views given by the interviewees on the issue of implementation of CAATTs and suggestion for successful implementation.

\section{LITERATURE REVIEW}

\subsection{Computer Assisted Audit Tools \& Technique (CAATTs)}

The term CAATTs can be referred to as any use of technology or specific software to assist auditors in performing audit and achieving the goals of auditing (Braun \& Davis, 2003; Sayana, 2003). CAATTs is defined as computer-based tools and techniques that are used by the auditors to increase their personal productivity as well as that of the audit function (Coderre, 2009). CAATTs is one of the audit tools that is widely used by auditors to audit financial statement. It is employed by auditors to extract and analyze client data (Braun \& Davis, 2003). Audit work can be performed efficiently and effectively by using CAATTs. Among the types of CAATTs used by auditors are electronic working paper, information retrieval and analysis, fraud detection, network security, electronic commerce and internet security, continuous monitoring, audit reporting, a database of audit history, computer-based training, and time tracking (Grand, 2001). CAATTs include Generalized Audit Software (GAS), Audit Command Language (ACL), Interactive Data Extraction and Analysis (IDEA), Utility Software, and many others (Karkar, 2002; Mahzan \& Lymer, 2009; Belfo \& Trigo, 2013; Mahzan \& Lymer, 2014).

\subsection{Important of IT and CAATTs}

The use of computer and IT by most of the organizations is to develop their business support and improve information processing activities has led to the increase in the need for CAATTs in such businesses to allow auditors to perform their review and monitoring tasks effectively (Mahzan \& Lymer, 2010; Asgari et al., 2013). CAATTs improve audit 
effectiveness and efficiency during the planning, conduct, reporting, and follow-up phases of the audit, as well as improving the overall management of the audit function (Coderre, 2009). The use of the computer enables auditors to perform tasks that would be impossible or extremely time-consuming to perform manually. The computer is the ideal tool for sorting, searching, matching, and performing various types of tests and mathematical calculations on data. Automated tools can remove the restrictions of following rigid manual audit programs as a series of steps that must be performed. The use of CAATTs allows the auditor to independently access the data stored on a computer system without dependence on the client (Rosli et al., 2012). CAATTs allow auditors to probe data and information interactively and to react immediately to the findings by modifying and enhancing the initial audit approach (Coderre, 2009). Thus, IT audit work can be performed efficiently, efficiently and reduce audit time. The productivity of the auditors can be increased when audit works are being done more effectively and efficiency (Zainol et al., 2017). Furthermore, the advantages of CAATTs (GAS) are ease of use, a huge data processing capability, a read-only aspect, the ability to import data presented variously, and provisions of required auditing functions such as statistics, sampling, audit trails and others (Sun, 2012).

\subsection{Barriers to Adopt CAATTs}

According to Mahzan and Lymer (2009), one of the barriers is technical complexity. Resolving technical issues such as the preparation of data for interrogation and analysis is the most prominent barriers to CAATTs implementation. Downloading data from the host system requires technical IT skills and knowledge as the data may be stored in various forms and once these data are downloaded it may need to be converted into a format and language understandable by the audit software. This can be a difficult task if auditors do not have the necessary technical knowledge. Other barrier is the attitude of the auditors (Mahzan \& Lymer, 2009). Auditors may be the ones not willing to change the way audits are performed. They are complacent with the manual auditing technique and not willing to explore CAATTs usage.

Sun (2012) stated that the communication barriers caused by different expertise prohibit the implementation of CAATTs projects. For example, IT staffs tend to use the same platform and programming language with enterprise information systems, so auditors find it difficult to accept the software.

Asgari et al. (2013) indicated that unfamiliarity of employees, managers, and auditors with CAATTs is the most critical barriers to using CAATTs. Other barrier is the high cost of training employees, managers, and auditors. Phua, Lau and Chris (2011) stated that the audit firms in Malaysia are facing challenges in CAATTs adoption due to constraints on resources, which are physical resources, intellectual resources, human resources, financial resources, and organisational resources.

\subsection{Successful Implementation of CAATTs}

Successful implementation of CAATTs requires the involvement of auditors and professionals in different fields, such as systems analysts, database managers, application software vendors, and others (Rezaee et al., 2001). Mahzan and Lymer (2009) pointed several factors for successful implementation of CAATTs, which is CAATTs champions and expert users should exist or be developed in the organization, support from the management on the overall adoption process, enthusiasm and commitment of adopters, cooperation from other departments, ability to demonstrate the benefits of the adoption to stakeholders (management and other department), good understanding of the 
host system to facilitate data access, ability to download data, training provided on CAATTs usage, user manual for CAATTs implementation, and regular usage of CAATTs.

\section{METHOD}

This study used the interview technique to get responses from internal auditors in the public sector. Interviewees for this research were drawn based on the public-sector organization in Malaysia, which were categorised into the federal level and state level whereby federal level covers ministry, federal statutory body and public university while state-level covers office of the state secretary, local government and state statutory body. Two government agencies were selected for each of the categories. This makes it a total of 12 organizations have been selected to be interviewed.

This research adopted semi-structured interviews with 12 head of internal auditors that representing the selected organization. The semi-structured interview protocol guided the interview to ensure the research question was addressed. This approach supported the research contribution of increased professional understanding and academic comprehension of CAATTs.

\section{FINDINGS}

Respondents have been asked about the practice of CAATTs in their internal audit department. The findings from the interview have been grouped into three sections based on the level of usage of CAATTs.

\subsection{High Usage of CAATTs}

It has been found that five out of 12 of the respondents mentioned that they do implement CAATTs in auditing. Specifically, most of them used generalised audit software (GAS) in their audit works. Out of five of the respondents, only two organisations have been using CAATTs extensively (i.e. more than $50 \%$ of CAATTs usage).

One of them has implemented ACL since 2009. The software although has been bought in 2007, it is however only being fully utilised since 2009 in which $70 \%$ of their audit works must use ACL. The IAU has their server to store all the information about the data. The used of ACL also has been set as part of internal auditor's KPI. All of the auditors need to know and use ACL. The use of ACL has been implemented in risk assessment, petrol card consumption, IT assets, fund utilisation, payroll, asset misappropriation, future audit, purchase, procurement and payment, income and cash collection. Among the reasons given are the use of $A C L$ can save the audit time and cost. It is also would be more efficient and can improve quality of audit reporting. According to their head of the IAU, ACL can be used for fraud detection and identify anomalies in payment trends. Among all of the respondents being interviewed, this is the only IAU that have very positive feedback on CAATTs implementation. The head of IAU had played their vital role to make sure the investment of CAATTs has been fully utilised. His passion and encouragement to motivate the auditors and the IAU staff to make use of the audit software that has been purchased.

We did ask about the critical success factor of CAATTs implementation. One of the main strategies is to include the ACL usage as part of the IAU's strategic plan. It is also has been included as part of the auditor's KPI. The IAU also has focused on the investment on the ACL and make sure they have resources and expertise available. Among other strategy, they also have their knowledge management system that store the ACL audit programme, user manual, audit working papers and reports as part of the continuing 
education to their audit staff. The IAU also has a strategic partnership with the software vendor. Thus, all the updates related to the software and the training needed can be delivered and obtained on time.

In another organisation, CAATTs also have been used extensively by the IAU as part of their continuous auditing program. Instead of ACL, they also used IDEA and advanced features in Microsoft Excel such as Pivot Table as part of e-auditing. For the working papers, they, however, prepared it manually either by using Microsoft Words or Microsoft Excel. The interviewee also explained that the audit report was being prepared using Microsoft Word and save in folder as part of the organisation's knowledge management storage.

Both of the above respondents were the only organisation in which the CAATTs has been fully utilised through the use of ACL, IDEA and Microsoft Excel.

\subsection{Minimal Usage of CAATTs}

The second group of respondents is categories as those who minimally use CAATTs where the use of CAATTs is less than $50 \%$ of their audit works. Three of the total respondents fall under this category. The third respondents mentioned that the percentage of using ACL is $30 \%$ of their audit work such as to analyse the data of procurement, tender and payroll. While the rest of their audit works are still based on the conventional method.

The fourth respondent responded that they do use ACL. However, it is more into sampling, filter sample project and for specific audit case. Currently, they need to rely on IT personnel from the IT department to use ACL. According to them, they are in the process of applying for IT auditor to be positioned directly under the IAU. While the ACL seems to be used in various areas of auditing the first two of organisations in the previous section, the perspective from the fourth respondent is different. According to them, "ACL is more on the audit of financial statement in which they are not focused on that."

While other was explicitly focused of data extraction and analysis tools such as ACL, IDEA and Microsoft Excel, the fifth respondent mentioned that they have an integrated system called Audit Management Systems which has been incorporated with Enterprise Risk Management Systems (ERMS).

\subsection{Not Using CAATTs}

Seven out of 12 respondents were not used CAATTs in their IAU. Due to the lack of expertise especially in the use of audit software, surprisingly, it is found that one of the respondents has purchased ACL, but it was not being utilised at all. The respondent further explained that they had planned to use the audit software but because of the use of it is not mandatory and it is quite hard to implement it especially to auditors who are not really IT literate, they prefer to use the traditional audit procedure instead.

Another factor of low usage of CAATTS that been given by a few of the other respondents are include; the auditor has no interest in IT, no IT background, awareness of top management about CAATTs and the courage of them to enforce their staff to use CAATSs. Some of the other respondents added that the factor of lack of use of ACL or other type of CAATTs is because of the systems itself or the attitude of auditors.

Contrary, the other auditor from one of the local government has mentioned that they actually can access and view the transactions through the application systems used by the auditee. However, there are no specific tools has been used to analyse those transactions. 
Some of the auditors that being interviewed also did not really focus on CAATTs or any specific audit software due to the scope of their audit were not require them to implement such technology.

The IAU does encourage their auditors to use the technology in auditing. However, the technology that has been implemented is out of the scope of CAATTs such as using computerised self-auditing systems for accountability index, using Microsoft Office for audit report (Microsoft Word), audit presentation (Microsoft PowerPoint), and email (Microsoft Outlook).

\section{CONCLUSION}

Studies conducted emphasize that auditors need to use the modern technology as in the current digital world, all of the auditee data have been stored electronically (Ahmi \& Kent, 2013). It is critical for the auditors to change from the traditional audit to the use of CAATTs or any other types of technologies that currently evolve in the era of Industrial Revolution 4.0 such as artificial intelligence, robotics, the Internet of Things, nanotechnology and biotechnology. Another concerning issue that requires auditors to use the technology is about how the auditors have been prepared to address the Big Data.

However, as demonstrated by the findings obtained in the current study, the implementation of CAATTs or other latest technology by auditors in the public sector are very minimal. Although most of the auditors realised about the benefits that have been provided by using the CAATTs, it seems that the courage taken by them are relatively slow unless there is a push factor that can motivate them to use such technology.

It is also an undeniable fact that the auditor is still relying on the traditional audit. Their knowledge and skill need to be upgraded with the use of latest technology and tools that will help them to audit the auditee's digital data.

\section{ACKNOWLEDGEMENTS}

This research was supported financially by the Ministry of Higher Education Malaysia (FRGS-SO Code: 12929). We thank the reviewers and associate editor for their comments, which improved this manuscript.

\section{REFERENCES}

Abu-Musa, A.A. (2008), Information technology and its implications for internal auditing: An empirical study of Saudi organizations. Managerial Auditing Journal, 23(5), 438-466.

Ahmi, A., Kent, S. (2013). The utilisation of generalized audit software (GAS) by external auditors, Managerial Auditing Journal, 28(2), 88 - 113

Ahmi, A., Saidin, S. Z., Abdullah, A., Che Ahmad, A., \& Ismail, N. A. (2016). State of Information Technology Adoption by Internal Audit Department in Malaysian Public Sector. International Journal of Economics and Financial Issues, 6(7s), 103-108.

Asgari, J., Soleimaniam, M., \& Goli, M. D. (2013). The Barriers of Using Computer-Assisted Auditing Techniques in the Private-Sector Auditing Enterprises in Iran. Journal of Basic and Applied Scientific Research, 3(4), 683-686.

Belfo, F., \& Trigo, A. (2013). Accounting Information Systems: Tradition and Future Directions. Procedia Technology, 9, 536-546.

Braun, R. L. \& Davis, H.E. (2003). Computer Assisted Audit Tools and Techniques: Analysis and Perspectives. Managerial Auditing Journal, 18 (9), 725-731.

Coderre, D. (2009). Internal Audit: Efficiency Through Automation. New Jersey: John Wiley \& Sons. 
Grand, C. L. (2001). Use of Computer-Assisted Audit Tools and Technique (CAATTs) Part 1, IT Audit, 4, The Institute of Internal Auditor. Retrieved 8 January 2017 from https://www.auditnet.org/audit-library/computer-assisted-audit-tools-and-techniques-caatt.

Karkar, K. V. (2002). Computer Assisted Audit Techniques. Retrieved 22 January 2017, from http://www.lexsite.com/services/network/caa/ar23-d.shtml

Mahzan, N. \& Lymer, A. (2014). Examining the Adoption of Computer-Assisted Audit Tools and Techniques: Cases of Generalized Audit Software Use by Internal Auditors. Managerial Auditing Journal, 29 (4), 327-349.

Mahzan, N., \& Lymer, A. (2009). Examining adoption of computer-assisted audit tools and techniques (CAATTs) by internal auditors: Cases of UK internal auditors. Proceedings of 12th International Business Information Management Association (IBIMA) Conference (pp. 1-46). Kuala Lumpur, Malaysia.

Perbendaharaan Malaysia (2004). Pekeliling Perbendaharaan Bil. 9 Tahun 2004: Pelaksanaan Audit Dalam di Kementerian/Jabatan Persekutuan dan Kerajaan Negeri.

Phua, L. K., Lau, A. H. P., \& Patel, C. (2011). Competitive advantages of audit firms in the era of international financial reporting standards: An analysis using the Resource-Based View of the firm. 2010 International Conference on E-Business, Management and Economics, 3, 308-313.

Rezaee, Z., Elam, R. \& Sharbatoghlie, A. (2001). Continuous Auditing: The Audit of the Future. Managerial Auditing Journal, 16(3), 150-158.

Rosli, K., Yeow, P. H. P. \& Siew, E. G. (2012). Factors influencing audit technology acceptance by audit firms: A new I-TOE adoption framework. Journal of Accounting and Auditing: Research \& Practice, 1-11.

Sayana, S. A. (2003). Using CAATs to Support IS Audit, Information Systems Control Journal, 1, 21-23.

Sun, C-M. (2012). From CAATTs Adoption to Continuous Auditing Systems Implementation: An Analysis Based on Organizational Routines Theories. MIS Review, 17 (2), 59-85.

Weidenmier, M. L. \& Ramamoorti, S. (2006), Technology and internal auditing. Journal of Information Privacy and Security, 20(1), 205-219.

Zainol, S. S., Samsuri, A. S., Tunku Arifin, T. R., Hussin, S., Othman, M. S., \& Jie, S. J. (2017). Determinants of Computer Assisted Audit Techniques (CAATs) Adoption. A Study in Small and Medium Practices in Malaysia. European Journal of Business and Social Sciences, 6(2), 135-150. 